\title{
New insights into long noncoding RNAs and their roles in glioma
}

\author{
Zixuan Peng ${ }^{1,2}$, Changhong Liu ${ }^{2}$ and Minghua $\mathrm{Wu}^{1,2^{*}}$
}

\begin{abstract}
Glioma is one of the most prevalent types of primary intracranial carcinoma with varying malignancy grades I-IV and histological subtypes, including astrocytomas, glioblastoma multiform (GBM), oligodendrogliomas and mixed tumors. Glioma is characterized by rapid cell proliferation and angiogenesis, and the WHO grade IV glioblastoma, which is highly malignant with poor prognosis because GBM stem-like cells (GSCs) are resistant to conventional therapy and easily recrudescent, accounts for the majority of gliomas. Consequently, investigations exploring the accurate molecular mechanisms and reliable therapeutic targets for gliomas have drawn extensive attention.

Based on the increasing amount of functional IncRNAs aberrantly expressed in glioma tissues and cell lines, IncRNAs might be critical for glioma initiation, progression and other malignant phenotypes. This review summarizes the latest insights into the IncRNA field and their functional roles in glioma, therefore evaluating the potential clinical applications of IncRNAs as prospective novel biomarkers and therapeutic targets.
\end{abstract}

Keywords: LncRNAs, Non-coding RNA, Glioma, Biomarker, Therapeutic targets

\section{Background}

LncRNAs comprise a wide variety of RNA transcripts of sizes greater than 200 nucleotides (nt) that lack significant protein-coding capacity [1], typically with 5 ' $\mathrm{m} 7 \mathrm{G}$ caps and $3^{\prime}$ poly(A) in tails, similar to the structure of mRNAs [2], but are more tissue-specific and dynamic than mRNAs, suggesting that these molecules have distinct biological roles [3]. LncRNAs were initially implicated in the epigenetic regulation of $\mathrm{X}$ chromosome inactivation during embryogenesis [4]. The last several years has seen a steady increasing interest in identifying lncRNAs and understanding their regulatory functions in almost all aspects from gene expression to protein translation and stability [5], either in cis (regulate neighboring genes) or in trans (regulate distant genes) [6]. (Table 1).

In accordance with their significant roles in extensive biological processes, lncRNAs have been implicated in

\footnotetext{
* Correspondence: wuminghua554@aliyun.com
${ }^{1}$ Hunan Provincial Tumor Hospital and the Affiliated Tumor Hospital of

* Correspondence: wuminghua554@aliyun.com
${ }^{1}$ Hunan Provincial Tumor Hospital and the Affiliated Tumor Hospital of

Xiangya Medical School, Central South University, Changsha, Hunan 410006, China

${ }^{2}$ Cancer Research Institute, School of Basic Medical Science, Central South University, Key Laboratory of Carcinogenesis and Cancer Invasion, Ministry of Education, Key Laboratory of Carcinogenesis, Ministry of Health, Changsha, Hunan 410078, China
}

(c) The Author(s). 2018 Open Access This article is distributed under the terms of the Creative Commons Attribution 4.0 International License (http://creativecommons.org/licenses/by/4.0/), which permits unrestricted use, distribution, and reproduction in any medium, provided you give appropriate credit to the original author(s) and the source, provide a link to the Creative Commons license, and indicate if changes were made. The Creative Commons Public Domain Dedication waiver (http://creativecommons.org/publicdomain/zero/1.0/) applies to the data made available in this article, unless otherwise stated. the onset and progression of cancer malignancy, including glioma, such as stemness, proliferation, angiogenesis and drug resistance $[7,8]$. Moreover, aberrant lncRNA expression profiles in clinical glioma specimens correlates with malignancy grade and histological differentiation, which have important clinical implications in glioma diagnosis of sub-classification [9] and prognostication $[10,11]$. In addition, IncRNAs transmitted from cell to cell participate in intercellular communications for maintaining microenvironment homeostasis or mediating tumor metastasis. This review summarizes the most up-to-date knowledge regarding how lncRNAs function at the molecular level and their implications in the areas of glioma research and therapy.

\section{LncRNA categories and structures}

LncRNA classification based on genomic location

LncRNAs can be classified into the following five categories according to their genomic location relative to neighboring protein-coding genes [12]: sense, antisense, bidirectional [13], intronic [14] and intergenic (lincRNAs) [1] (more detail in Fig. 1). Moreover, the promoter upstream transcripts (PROMPTs) and enhancer-associated RNAs (eRNAs), transcribed from promoters or enhancers, show some similarities in functional mechanism with 
Table 1 Examples of IncRNA functional mechanisms

\begin{tabular}{|c|c|c|c|c|}
\hline Primary mechanism & LncRNA & Detailed mechanism & Function & Reference \\
\hline \multirow[t]{5}{*}{$\begin{array}{l}\text { Chromatin } \\
\text { modification }\end{array}$} & LncPRESS1 & $\begin{array}{l}\text { Disrupt deacetylation of H3K56 by } \\
\text { sequestering SIRT6 from chromatin }\end{array}$ & Safeguard the stem cells pluripotency & [17] \\
\hline & NEAT1 & $\begin{array}{l}\text { Bind to } E Z \mathrm{H} 2 \text { and mediate the trimethylation } \\
\text { of } \mathrm{H} 3 \mathrm{~K} 27 \text { in their promoters. }\end{array}$ & $\begin{array}{l}\text { Promote glioma cell growth and invasion by } \\
\text { increasing } \beta \text {-catenin nuclear transport }\end{array}$ & [25] \\
\hline & HOTTIP & $\begin{array}{l}\text { Maintain gene transcription by binding to } \\
\text { adaptor WDR5 }\end{array}$ & $\begin{array}{l}\text { Promote hepatic carcinoma tumorigenesis and } \\
\text { disease progression }\end{array}$ & [26] \\
\hline & FOXC1 & Stabilize enhancer-promoter looping & $\begin{array}{l}\text { Involved in many regulated programs in breast } \\
\text { cancer }\end{array}$ & [15] \\
\hline & NBAT-1 & $\begin{array}{l}\text { Activate the neuronal-specific transcription } \\
\text { factor NRSF/REST }\end{array}$ & Contribute to aggressive neuroblastoma & [51] \\
\hline \multirow[t]{2}{*}{ Alternative splicing } & SPA1, SPA2 & $\begin{array}{l}\text { Bind to target mRNAs and sequester multiple } \\
\text { RBPs to regulate alternative splicing }\end{array}$ & Involved in Prader-Willi syndrome pathogenesis & [21] \\
\hline & LncRNA BC200 & $\begin{array}{l}\text { Bind to } \mathrm{BCl}-\mathrm{x} \text { pre-mRNA and recruit splicing } \\
\text { factor hnRNP A2/B1 }\end{array}$ & $\begin{array}{l}\text { Modulate Bcl-x alternative splicing in breast } \\
\text { cancer }\end{array}$ & [28] \\
\hline \multirow[t]{3}{*}{$\begin{array}{l}\text { mRNA stability/ } \\
\text { modification }\end{array}$} & KRT7-AS & $\begin{array}{l}\text { Form "IncRNA-mRNA" protective duplex at } \\
\text { overlapping region }\end{array}$ & Promote gastric cancer cell migration & [27] \\
\hline & MEG3 & $\begin{array}{l}\text { Act as RNA scaffold to form PTBP1-mediated } \\
\text { Shp RNA decay }\end{array}$ & $\begin{array}{l}\text { Promote hepatocirrhosis in hepatocellular } \\
\text { carcinoma }\end{array}$ & [29] \\
\hline & FOXM1-AS & $\begin{array}{l}\text { Facilitate interaction of ALKBH5 and FOXM1 } \\
\text { mRNA to demethylate FOXM1 mRNA }\end{array}$ & $\begin{array}{l}\text { Enhance self-renewal and tumorigenesis of } \\
\text { glioblastoma stem-like cells }\end{array}$ & [50] \\
\hline \multirow[t]{2}{*}{ miRNA sponge } & TP73-AS1 & $\begin{array}{l}\text { Increase HMGB1 expression by sponging } \\
\text { miR-142 }\end{array}$ & Promote glioma proliferation and invasion & [76] \\
\hline & CASC2 & $\begin{array}{l}\text { Inhibit miR-181a activity with RISC complex } \\
\text { participation }\end{array}$ & Sensitize TMZ-resistant glioma cells to TMZ & [45] \\
\hline \multirow[t]{3}{*}{$\begin{array}{l}\text { Change protein } \\
\text { activity/localization }\end{array}$} & HULC & $\begin{array}{l}\text { Scaffold of kinase and YB-1 to promote YB-1 } \\
\text { phosphorylation }\end{array}$ & $\begin{array}{l}\text { Accelerate the translation of tumorigenesis } \\
\text { mRNAs in hepatocellular carcinoma }\end{array}$ & [31] \\
\hline & LINK-A & Facilitate BRK-dependent HIF1a phosphorylation & $\begin{array}{l}\text { Promote breast cancer glycolysis reprogramming } \\
\text { and tumorigenesis }\end{array}$ & [18] \\
\hline & SNHG5 & $\begin{array}{l}\text { Trap MTA2 in the cytosol and prevent it } \\
\text { translocation into nucleus. }\end{array}$ & Suppress gastric cancer progression & [32] \\
\hline \multirow[t]{2}{*}{$\begin{array}{l}\text { Encode functional } \\
\text { micropeptides }\end{array}$} & LINC00948 & $\begin{array}{l}\text { Translate myoregulin, which inhibit } \\
\text { sarcoplasmic reticulum Ca2 +-ATPase }\end{array}$ & $\begin{array}{l}\text { Regulate Ca2+ uptake and skeletal muscle } \\
\text { contractility }\end{array}$ & [34] \\
\hline & LINC00961 & $\begin{array}{l}\text { Generate SPAR, which interact with } \\
\text { lysosomal v-ATPase }\end{array}$ & $\begin{array}{l}\text { Modulate skeletal muscle regeneration after } \\
\text { injury }\end{array}$ & [35]. \\
\hline \multirow[t]{3}{*}{$\begin{array}{l}\text { Intercellular } \\
\text { communication }\end{array}$} & LncARSR & $\begin{array}{l}\text { Transmit from sunitinib-resistance cell to } \\
\text { sensitive cells }\end{array}$ & $\begin{array}{l}\text { Confer Sunitinib resistance to sensitive cells in } \\
\text { renal cancer }\end{array}$ & [39] \\
\hline & $\mathrm{H} 19$ & $\begin{array}{l}\text { Transmit from cancer stem-cell-like (CSC) to } \\
\text { endothelial cells }\end{array}$ & Promote angiogenesis in hepatic carcinoma & [40] \\
\hline & $\begin{array}{l}\text { ENST00000444164 } \\
\text { ENST0000043768 }\end{array}$ & $\begin{array}{l}\text { Transmit from epithelial ovarian cancer (EOC) } \\
\text { to endothelial cells }\end{array}$ & $\begin{array}{l}\text { Promote epithelial ovarian cancer cells } \\
\text { migration }\end{array}$ & [41] \\
\hline
\end{tabular}

regulatory DNA elements [12]. For instance, eRNAs likely facilitate enhancer and promoter interactions and thereby activate target genes [15].

\section{LncRNA categories based on subcellular localization}

Since the functional mechanism of lncRNAs depends on their subcellular localization [16], IncRNAs can also be grouped into nuclear or cytoplasmic categories [5]. LncRNAs that exhibit distinct nuclear localization patterns typically alter gene transcription via transcriptional interference [17] and chromatin remodeling [15], whereas lncRNAs exported to the cytoplasm perform regulatory roles by mediating RNA processing, affecting mRNA stability or directly regulating protein function [18].

\section{New LncRNA species based on unique structures}

Given that lncRNAs structures are associated with their stability and functional mechanisms [16], the identification of lncRNA secondary structures will contribute to their applications in clinical medicine [19]. Most linear lncRNAs have 5'm7G caps and 3' poly(A) tails, similar to mRNAs, while some noncanonical terminal lncRNAs processed with unique transcription patterns can be defined as new RNA species [20]. Sno-lncRNAs and SPA- 


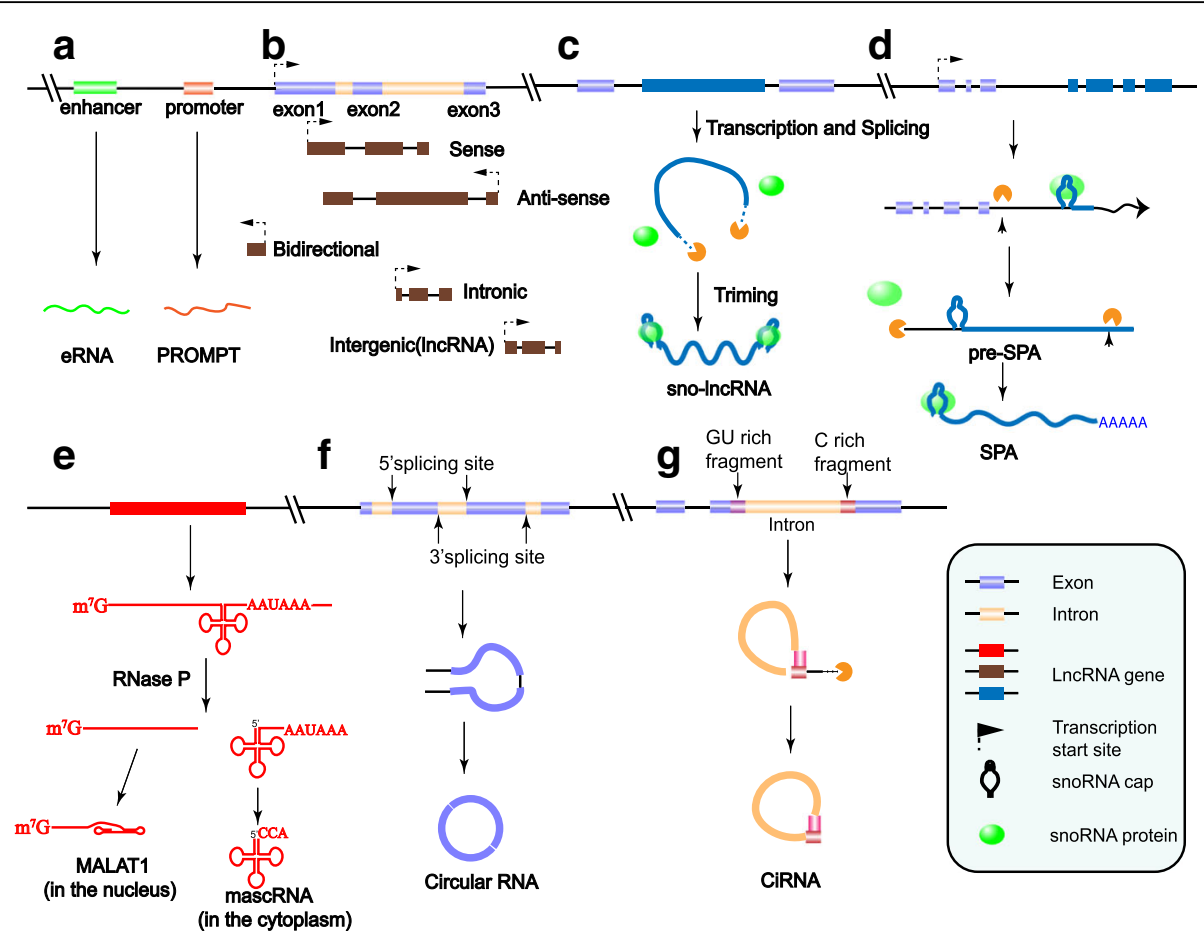

Fig. 1 Schematic representation of IncRNA species and structures. a LncRNAs transcribed from functional DNA element regions: promoter upstream transcript (PROMPTs), enhancer-associated RNA(eRNAs); (b) Mainstream five categories based on genomic location and transcript orientation of IncRNA: (1) sense IncRNAs and (2) antisense IncRNAs, overlapping and transcribed from the same or opposite strand of protein-coding genes, (3) bidirectional IncRNAs, typically transcribed in the opposite direction of its neighboring protein-coding gene (less than 1 kb away) [13], (4) intronic IncRNAs, transcribed entirely from introns [14], (5) intergenic IncRNAs (lincRNAs), transcribed from genomic interval [1]; (c, d) LncRNAs characterized by snoRNA caps: Sno-IncRNAs have snoRNA caps at both ends, while SPA-IncRNAs possess 5' snoRNA only; (e) LncRNAs characterized by tRNAlike extremities, with the 3' end alternatively processed by ribonuclease P (RNase P), e.g., MALAT1 and NEAT1_2; (f, g) LncRNAs with close circular structures: derived from back-splicing of exons named circular RNAs, and ciRNAs are produced from intron lariats.

lncRNAs [21] are characterized by snoRNA caps at both ends or only at the $5^{\prime}$ terminus, having longer half-lives than other IncRNAs. In addition, the RNase P-mediated processing of lncRNAs results in tRNA-like structures at the extremity and increased stability in the cytoplasm, for which a typical example is MALAT1 [22]. As for lncRNAs that exist in loop form, there are circular RNAs [23] and circular intronic RNAs (ciRNAs) [24] produced from the back-splicing of exons or introns respectively (Fig. 1).

\section{Functional mechanisms of IncRNAs in glioma and other cancers}

\section{LncRNAs regulate genome activity}

Unsurprisingly, many lncRNAs participate in the epigenetic regulation of gene expression by recruiting chromatin modifiers (e.g., EZH2/PRC2 [25] and WDR5/TrxG [26]) to a specific genomic location as a Scaffold, segregating chromatin modifiers away from their regulatory targets as a Decoy [17] or mediating the 3D organization of chromosomes [15].

In glioma, NEAT1 mediates the trimethylation of $\mathrm{H} 3 \mathrm{~K} 27$ in the promoter region of $\mathrm{WNT} / \beta$-catenin pathway negatively regulated factors (Axin2, ICAT and GSK3B) by physically interacting with the PRC2 subunit EZH2 as a Scaffold, thereby resulting in WNT/ $\mathrm{W}$-catenin pathway activation [25]. During hepatocarcinogenesis, IncRNA HOTTIP directly interacts with the trithorax group (TrxG) protein WDR5 and induces an open DNA-chromatin configuration to target WDR5/MLL complexes, driving $\mathrm{H} 3 \mathrm{~K} 4$ trimethylation and thus promoting the transcription of HOXA locus genes [26]. Increased by estradiol (E2) stimulation in breast cancer, FOXC1 contributes to E2-dependent gene activation by promoting the $3 \mathrm{D}$ contacts between the specific promoter and enhancer cluster and increasing the strength of enhancer-promoter looping [15].

\section{LncRNAs related to posttranscriptional regulation}

Aside from regulating the alternative splicing [21] and stability [27] of mRNAs, the competing endogenous RNAs (ceRNAs) or miRNA sponge mechanism are also implicated in lncRNAs post-transcriptional regulation. (Detailed in Table 2).

During mRNA alternative splicing, lncRNA BC200 recruits splicing factors hnRNP A2/B1 to Bcl-x pre-mRNA 
Table 2 Deregulated IncRNAs in glioma

\begin{tabular}{|c|c|c|c|c|}
\hline & LncRNA & Mechanisms & Function & References \\
\hline \multirow[t]{18}{*}{ Up-regulated } & NEAT1 & $\begin{array}{l}\text { Bind to } \mathrm{EZH} 2 \text { and mediate } \mathrm{H} 3 \mathrm{~K} 27 \mathrm{me} 3 \text { in target } \\
\text { promoters. }\end{array}$ & Promote glioma cell growth and invasion & {$[25]$} \\
\hline & \multirow[t]{3}{*}{ HOTAIR } & Interact with the PRC2 complex & Promotes glioblastoma cell cycle progression & {$[52]$} \\
\hline & & HOTAIR/miR-326/FGF1 axis & $\begin{array}{l}\text { Promotes malignant biological behaviors of glioma } \\
\text { cells }\end{array}$ & {$[43]$} \\
\hline & & $\begin{array}{l}\text { Bind to miR-148b-3p as ceRNA and enhance tight } \\
\text { junction }\end{array}$ & Decrease the permeability of BTB in glioma & {$[62]$} \\
\hline & TUG1 & $\begin{array}{l}\text { Inhibit miR-144 and reverse miR-144 effect on occludin, } \\
\text { ZO-1 and claudin-5 }\end{array}$ & Regulate BTB permeability in glioma & {$[63]$} \\
\hline & FOXM1-AS & $\begin{array}{l}\text { Facilitate interaction of ALKBH5 and FOXM1 mRNA to } \\
\text { demethylate FOXM1 mRNA }\end{array}$ & $\begin{array}{l}\text { Enhance self-renewal and tumorigenesis of } \\
\text { glioblastoma stem-like cells }\end{array}$ & {$[50]$} \\
\hline & \multirow[t]{3}{*}{ CRNDE } & Modulate the mTOR signaling pathway. & Promote glioma cell growth and invasion & {$[42]$} \\
\hline & & Attenuate miR-384/PIWIL4/STAT3 axis & $\begin{array}{l}\text { Facilitate glioma cells proliferation and invasion, } \\
\text { while inhibited cells apoptosis }\end{array}$ & {$[30]$} \\
\hline & & $\begin{array}{l}\text { Bind to miR-136-5p as ceRNA, thereby protecting } \\
\mathrm{Bcl}-2 \text { and Wnt2 }\end{array}$ & $\begin{array}{l}\text { Enhance migratory and invasive capacities of } \\
\text { glioma cells }\end{array}$ & {$[77]$} \\
\hline & \multirow[t]{2}{*}{$\mathrm{H} 19$} & $\begin{array}{l}\text { Up-regulate the VASH2 expression by decreasing } \\
\text { miR-29a. }\end{array}$ & $\begin{array}{l}\text { Promote glioblastoma cell invasion, angiogenesis } \\
\text { and tube formation }\end{array}$ & {$[57]$} \\
\hline & & Derive miR-675, which directly suppresses CDK6 & Promote glioma cell proliferation and migration & {$[78]$} \\
\hline & SOX2OT & $\begin{array}{l}\text { Bind to both miR-194-5p and miR-122, reverse SOX3 } \\
\text { expression }\end{array}$ & $\begin{array}{l}\text { Promote proliferation, migration and invasion of } \\
\text { GSCs }\end{array}$ & {$[79]$} \\
\hline & ECONEXIN & Increase TOP2A by sponging miR-411-5p & Maintain aggressive proliferation of glioma cells & {$[46]$} \\
\hline & $\mathrm{HCP5}$ & Form HCP5-miR-139-RUNX1 positive feedback loop & $\begin{array}{l}\text { Induce proliferation, migration and invasion of } \\
\text { glioma cells }\end{array}$ & [53] \\
\hline & \multirow[t]{3}{*}{ XIST } & $\begin{array}{l}\text { Increase the expression of ZO-2 and transcription } \\
\text { factor FOXC1 as miR-137 sponge }\end{array}$ & $\begin{array}{l}\text { Decrease blood-tumor barrier permeability and } \\
\text { promote glioma angiogenesis }\end{array}$ & {$[58]$} \\
\hline & & $\begin{array}{l}\text { Form RNA induced silencing complex RISC with } \\
\text { miR-152 }\end{array}$ & Promote GSC proliferation, migration and invasion & {$[48]$} \\
\hline & & Downregulate miR-429 as sponge & promote glioma tumorigenicity and angiogenesis & {$[59]$} \\
\hline & $\mathrm{CASC} 2 \mathrm{C}$ & Compete to combine miR-101 by repelling CPEB1 & $\begin{array}{l}\text { Promote the malignant characteristic of astrocytoma } \\
\text { cells }\end{array}$ & {$[80]$} \\
\hline \multirow[t]{9}{*}{ Down-regulated } & NBAT-1 & $\begin{array}{l}\text { Suppress the neuronal-specific transcription factor } \\
\text { NRSF/REST }\end{array}$ & $\begin{array}{l}\text { Impair proliferation and increase differentiation of } \\
\text { neuroblastoma }\end{array}$ & [51] \\
\hline & \multirow[t]{2}{*}{ TUG1 } & $\begin{array}{l}\text { Recruit polycomb to methylate locus-specific histone } \\
\text { H3K27 }\end{array}$ & Maintain stemness features of GSCs & {$[47]$} \\
\hline & & Induce the activation of caspase- 3 and caspase -9 & Induced glioma apoptosis & {$[81]$} \\
\hline & \multirow[t]{2}{*}{ GAS5 } & $\begin{array}{l}\text { Form GAS5/miR-196a-5p/FOXO1 positive feedback } \\
\text { loop }\end{array}$ & $\begin{array}{l}\text { Suppress glioma stem cells proliferation, migration, } \\
\text { and invasion }\end{array}$ & {$[44]$} \\
\hline & & $\begin{array}{l}\text { Increase the expression of bmf and Plexin C1 by } \\
\text { downregulating miR-222 }\end{array}$ & Suppress glioma malignancy and tumor size & {$[82]$} \\
\hline & \multirow[t]{3}{*}{ MALAT1 } & Downregulate miR-155 expression & $\begin{array}{l}\text { Suppress the invasion and proliferation of glioma } \\
\text { cells }\end{array}$ & {$[54]$} \\
\hline & & $\begin{array}{l}\text { Attenuate ERK/MAPK-mediated growth and MMP2- } \\
\text { mediated invasiveness. }\end{array}$ & Suppress the growth and invasion of glioma cells & {$[56]$} \\
\hline & & Up-regulate EMT related proteins & Decrease the sensitivity of glioblastoma cells to TMZ & {$[65]$} \\
\hline & CASC2 & $\begin{array}{l}\text { Interact with miR-181a, increase the expression of } \\
\text { PTEN }\end{array}$ & $\begin{array}{l}\text { Inhibit glioma cells proliferation and amplify TMZ } \\
\text { sensibility }\end{array}$ & {$[45]$} \\
\hline
\end{tabular}

and contributes to breast cancer pathogenesis [28]. From the perspective of regulating mRNA stability, lncRNAs may either form protective "IncRNA-mRNA" duplex to stabilize mRNAs [27] or, conversely, facilitate mRNA degradation by recruiting RNA-binding proteins, such as PTBP1 to target pre-mRNA [29]. Moreover, LncRNAs can regulate the efficiency of mRNA translation. Upon energy stress, FILNC1 interacts with AUF1, a c-Myc 
mRNA-binding protein, and sequesters AUF1 from binding c-Myc mRNA, leading to the downregulation of c-Myc protein. Cytoplasmic lncRNAs can participate in the ceRNA regulatory network and act as endogenous miRNA sponges through direct base pairing. In highgrade GBM, the up-regulation of CRNDE competitively binds to miR-384 and decreases the availability of miR384 to its downstream target genes (STAT3, cyclin D1 and $\mathrm{Bcl}-2$ ), thus abrogating the suppression of miR-384 downstream genes [30].

\section{LncRNAs in protein modification and anchoring}

LncRNAs can also directly bind proteins essential for a signaling pathway and modulate their functions. A novel mechanism by which lncRNA plays an oncogenic role through modulating the phosphorylation status of its interaction protein is demonstrated in many cancers. LINK-A recruits breast tumor kinase (BRK) to phosphorylate Tyr565 of hypoxia-inducible factor $\alpha$ (HIF1 $\alpha$ ), and the activated HIF1 $\alpha$ signaling promotes breast cancer glycolysis reprogramming [18]. HULC specifically binds to YB-1 (translationally inactive ribonucleoprotein particle) and promotes YB-1 phosphorylation, which leads to the release of YB-1 from its bound mRNA. Consequently, the translation of silenced oncogenic mRNAs (cyclin D1, cyclin E1, and MMP3) in hepatocellular carcinoma would be activated [31].

Moreover, lncRNA SNHG5 can trap MTA2 in the cytoplasm, preventing MTA2 translocation into the nucleus and interfering with nucleosome remodeling. The significantly downregulated SNHG5 in gastric cancer, thereby promoting gastric cancer progression [32].

\section{LncRNAs encode functional micropeptides}

Recently, some lncRNAs have been shown to encode functional micropeptides based on small-ORFs [33]. For instance, micropeptides translated from lncRNAs regulate skeletal muscle regeneration or contractility by interacting with sarcoplasmic reticulum $\mathrm{Ca}^{2+}$-ATPase (SERCA) [34], lysosomal v-ATPase [35], or displacing SERCA inhibitors [36]. Moreover, the micropeptides encoded by lncRNA HOXB-AS3 competitively bind to hnRNPs, suppressing glucose metabolism reprogramming in colon cancer [37].

\section{Exosome-transmitted IncRNAs function as intercellular communicator}

LncRNAs play roles in intercellular communication, wherein the release of IncRNAs into the recipient cells can modulate cell phenotypes through the regulation of target signaling pathways [38]. Studies have shown that lncRNAs secreted from drug-resistant renal carcinoma cells via exosomes can transform adjacent drug-sensitive cells into a resistant phenotype [39]. Moreover, exosome- transmitted lncRNAs can regulate the tumor microenvironment and mediate the communication of heterogeneous cells [40, 41]. Through the release of exosomes containing lncRNA H19, CD90+ liver cancer cells can modulate the phenotypes of endothelial cells, promoting angiogenesis and cell-to-cell adhesion [40].

\section{LncRNAs regulate glioma malignant phenotypes}

Accumulating evidence has demonstrated that many dysregulated lncRNAs in glioma are closely related to tumorigenesis, metastasis and prognosis or therapies [7, 8] (Fig. 2 and Table 2). LncRNAs can function as molecular signaling mediators, modulating the expression of a certain set of genes and corresponding signaling pathways (e.g., the NEAT1-WNT/ $\beta$ catenin pathway [25] and CRNDE- mTOR signaling [42]).

The majority of the glioma-associated lncRNAs serve as "miRNA sponges" to quench miRNA activity (e.g., HOTAIR/miR-326 [43], Gas5/miR-196a-5p [44], CASC2/ miR-181a [45] and ECONEXIN /miR-411-5p [46]).

\section{LncRNAs related to glioma stemness}

Recent studies have shown that IncRNA TUG1 maintains the stemness of GSCs through epigenetically suppressing multiple neuronal differentiation-associated genes. TUG1 physically interacts with PRC2 components (EZH2 and SUZ12) and transcription factor YY1 as a protein scaffold, promoting the locus-specific methylation of histone H3K27 [47]. LncRNA GAS5 suppresses GSC proliferation, migration and invasion by binding to onco-miR-196a-5p and upregulating the downstream FOXO1. Interestingly, the increased FOXO1 promotes GAS5 transcription, thus forming a positive feedback loop [44]. LncRNA XIST promotes the proliferation and inhibits the apoptosis of GSCs. More than directly binding to miR-152 as a sponge, XIST is likely in the same RNA-induced silencing complex (RISC) with miR-152, thus abrogating miR-152 downstream pathways [48].

Post-transcriptional mRNA modification provides an additional regulation of mRNA stability, and N6methyladenosine $(\mathrm{m} 6 \mathrm{~A})$ is the most prevalent internal modification on mRNAs [49]. LncRNA FOXM1-AS promotes the interaction of FOXM1 nascent transcripts with RNAm6A demethylase ALKBH5, leading to the demethylation and elevated expression of FOXM1. The elevated expression of transcription factor FOXM1 then facilitates GSC self-renewal and tumorigenesis [50].

\section{LncRNAs related to glioma proliferation and migration}

Regulated by EGFR pathway activity, NEAT1 is critical for glioma cell growth and invasion through the $\mathrm{WNT} / \beta$-catenin pathway. NEAT1 mediates the H3K27 trimethylation of three $\mathrm{WNT} / \beta$-catenin pathway negatively regulated factors, thereby increasing $\beta$-catenin nuclear transport 


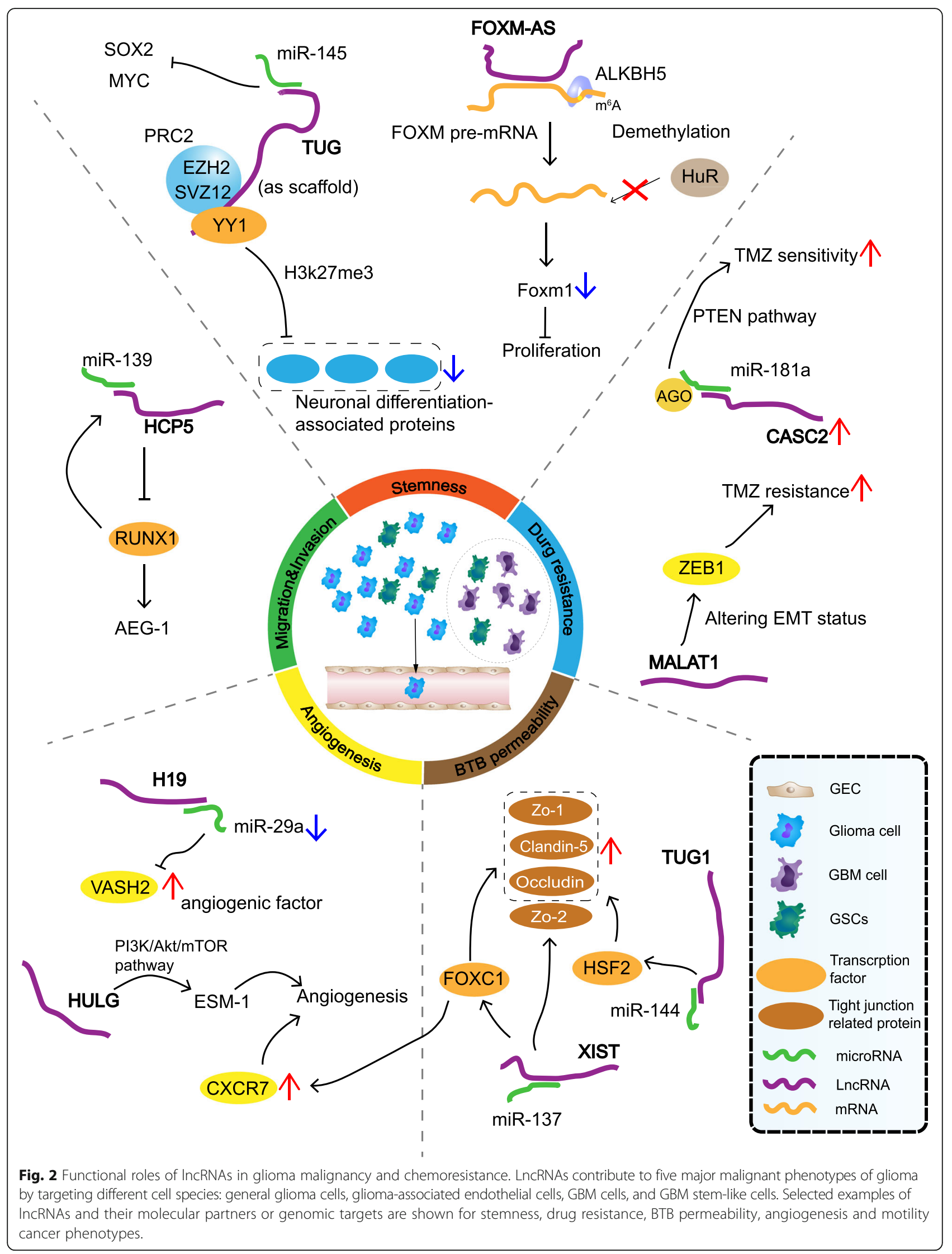


and rekindling the $\mathrm{WNT} / \beta$-catenin pathway [25]. Considering that NBAT-1 is expressed at low levels in highrisk neuroblastoma, NBAT-1 acts as a scaffold for EZH2 recruitment and represses NBAT-1/EZH2 target genes, which are involved in neuroblastoma progression [51]. It was demonstrated that the $5^{\prime}$ domain of HOTAIR can bind to the EZH2 and promote glioblastoma cell cycle progression [52].

The oncogene ECONEXIN is predominantly located in the cytoplasm and interacts with miR-411-5p via two binding sites, regulating TOP2A by sponging miR-411-5p in early glioma tumorigenesis [46]. Furthermore, lncRNA HCP5 sponge miR-139 to up-regulate RUNX1, and then RUNX1 feedback promoted HCP5 expression by binding to HCP5 promoters, creating a HCP5/miR-139/RUNX1 positive feedback loop to regulate the malignant behavior of glioma cells [53]. As a glioma-suppressor, MALAT1 inhibits cell viability by downregulating miR-155 expression [54], and a similar mechanism was also observed in the "TUSC7-miR-23b" axis [55]. The knockdown of CRNDE decreases the protein level of PIWIL4, a target of miR384, which leads to glioma regression in vivo [30].

MALAT1 play a tumor-suppressive role in glioma by attenuating ERK/MAPK-mediated growth and MMP2mediated invasiveness. The decreased level of MALAT1 in glioma significantly increased tumorigenicity in both subcutaneous and intracranial human glioma xenograft models [56].

Angiogenesis is a universal characteristic of blood vesselrich glioma progression that facilitates proliferation and migration. In glioma microvessels, the overexpression of H19 induces glioma-associated endothelial cells (GECs) proliferation, migration and tube formation via increasing the expression of angiogenic factor VASH2 as a miR-29a sponge [57]. Up-regulated XIST can facilitate glioma angiogenesis by increasing the promoter activity of chemokine receptor 7b (CXCR7) [58], or down-regulating miR-429 as a molecular sponge [59]. LncRNA HULC regulates ESM-1 via the $\mathrm{PI} 3 \mathrm{~K} / \mathrm{Akt} / \mathrm{mTOR}$ signaling pathway and hence plays a pro-angiogenesis role in human gliomas [60].

\section{LncRNAs related to invalid chemotherapy}

Conventional treatment of glioma includes surgical resection followed by radiotherapy and temozolomide (TMZ) chemotherapy. Invalid drug administration in glioma is mainly caused by either the poor permeability of the blood-tumor barrier (BTB), which invalidates adjuvant chemotherapy [61] or the acquired chemo-resistance of tumor cells.

Modulating the biological behaviors of glioma vascular GECs is an important aspect of lncRNAs influencing therapeutic effect. For example, HOTAIR decreases BTB permeability via binding to miR-148b-3p, which further increasing tight junction-related proteins (ZO-1, occludin and claudin-5) in GECs by regaining upstream stimulating factor 1 (USF1) [62]. Similarly, the aberrant high expression of lncRNA XIST in GECs reduces BTB permeability by increasing tight junction-related proteins (ZO-1, ZO-2 and occludin) [58]. LncRNA TUG1 is also up-regulated in endothelial cells and regulates BTB permeability through targeting miR-144 [63]. Some researches demonstrated that the knockdown of MALAT1 resulted in the increased permeability of BTB, which might contribute to the reworking of chemotherapeutics [61].

TMZ is a first-line chemotherapeutic drug most widely used for treating gliomas, whereas drug resistance is largely responsible for the failure of glioma chemotherapy [64]. Research has shown that cells with epithelial-tomesenchymal transition (EMT) characteristics tend to be more resistant to anticancer drugs. LncRNA MALAT1 is up-regulated in multidrug-resistant glioblastoma cell lines and decreases the sensitivity of glioblastoma cells to TMZ by up-regulating EMT-related proteins (ZEB1, Snail and SLUG) [65]. LncRNA CASC2 up-regulates the tumor suppressor PTEN through directly inhibiting miR-181a, thus amplify TMZ sensibility of glioma cells [45].

\section{Promising biomarker: IncRNAs in diagnostic or prognostic applications}

The aberrant lncRNA expression profiles in clinical specimens correlates with malignancy grade and histological differentiation, which have important clinical implications in the glioma diagnosis of sub-classification [9] and prognostication [10, 11]. One of the distinctive features of lncRNAs is their highly tissue- and cell typespecific expression patterns [3], which could accurately classify different subtypes of glioma and predict responses to treatments.

One-way analysis of variance (ANOVA) indicates a markedly significant difference in HOXA11-AS expression between the four GBM subtypes in CGGA mRNA microarray datasets, and HOXA11-AS expression in classical and mesenchymal subtypes is higher than that in neural and proneural subtypes, suggesting that HOXA11-AS might serve as a biomarker for identifying glioma molecular subtypes [9]. The up-regulated oncogene CRNDE is correlated with larger tumor size $(p=$ $0.011)$, higher WHO grade $(p=0.001)$, and recurrence $(p=0.008)$. Additionally, survival analysis demonstrated that up-regulated CRNDE expression is associated with poor overall survival of glioma patients $(p<0.001)$ [10]. Cox regression analysis revealed that HOXA-AS3 is an independent prognostic factor, and its high-expression is associated with tumor grade and poor prognosis in glioma patients [11].

As previously described, exosome-transmitted lncRNAs reflect the progress of the tumor microenvironment, 
which are stable and easily detectable in plasma or other body fluids and enable accurate diagnosis as desirable markers [66]. A potential application for minimally invasive liquid biopsy lies in the use of circulating lncRNA levels, which has been well documented in other cancers [67]. By comparing the expression of ten candidate circulating serum lncRNAs in a case-control study, three lncRNAs, LINC00152, RP11-160H22.5 and XLOC014172, have been identified as useful in the early diagnosis of hepatocellular carcinoma [68]. Moreover, lncRNAs with low expression levels in cells may be enriched in secreted exosomes for the regulation of cancer metastasis, thereby showing higher clinical utility [69].

\section{Therapeutics targeting tumor-specific IncRNA abnormalities}

Since the modulation of lncRNA networks mediates antiproliferative effects in malignant tumors and triggers therapeutic efficacy, targeting tumor-specific lncRNA abnormalities using small interfering RNAs (siRNAs) may be an effective strategy [70].

Many epigenetic inhibitors are currently used in clinical trials. For instance, bromodomain and extraterminal (BET) domain proteins reduce the levels of several oncogenes in glioblastoma, including lncRNA HOTAIR, and the use of BET inhibitor can restore the malignancy caused by oncogenic lncRNAs [71].

Antisense oligonucleotides (ASOs) can correct aberrant lncRNA networks by inducing RNase $\mathrm{H}$-dependent degradation or sterically blocking lncRNA activity. For example, intravenous treatment with ASOs targeting lncRNA TUG1 coupled with a drug delivery system induces glioma stem cell differentiation and efficiently represses tumor growth in vivo [47]. Furthermore, chemical modifications of ASOs, such as the addition of 2'-omethyl and locked nucleic acids at both $5^{\prime}$ and $3^{\prime}$ ends, can protect ASOs from degradation and maintain sufficient concentrations. A preclinical study demonstrated that the use of modified ASOs targeting MALAT1 in a breast cancer mouse model promotes cystic differentiation and decreases tumor growth [72].

To make "anti-ncRNA therapy" more thermally stable in the tumor microenvironment, specific nucleic acids conjugated with a neutral-charged peptide backbone, called peptide nucleic acids (PNAs), are modified for in vivo applications [73]. PNAs-based strategy blocks the ability of lncRNA HOTAIR to interact with EZH2, subsequently reduces HOTAIR-EZH2 activity and inhibits ovarian and breast cancer cell invasion, which may be suitable for other solid cancers, such as glioma [74].

With a better understanding of the lncRNA binding domain, the use of small molecule inhibitors to disrupt the interactions of lncRNAs with their binding partners, particularly the chromatin modification complex, is an alternative strategy, which has been demonstrated for miRNAs [75]. However, given the length of some lncRNAs, it is possible that extensive secondary structures will restrict the accessibility of small molecule inhibitors to crucial parts of target lncRNAs, again emphasizing the importance of structural mapping for lncRNAs [19].

\section{Conclusion}

At present, tens of thousands of identified lncRNAs have been associated with imbalanced gene regulation and aberrant biological processes in cancers [3, 6], and many lncRNAs play indispensable roles in the onset and progression of glioma malignancy, including the stemness, proliferation, angiogenesis and drug resistance $[7,8]$.

However, only a few functional mechanisms of lncRNAs have been well characterized, and some recent insights into lncRNAs identified in other diseases and cancers, such as molecules encoding tumor-related micropeptides, changes in the activities or conformation of proteins and the regulation of tumor microenvironment homeostasis, have not yet been clearly demonstrated in glioma pathogenesis. The majority of studies of glioma-associated lncRNAs are typically focused on ceRNA regulatory networks; thus, there is an urgent need to elucidate the detailed mechanisms of the roles of lncRNAs in glioma. Additionally, whether lncRNA expression in glioma is dysregulated and abnormal remains elusive, and the underlying mechanisms are still unknown.

Since lncRNAs mainly exert their functions by interacting with other biomolecules, the secondary structures of the interaction domains are of particular importance, and we anticipate that further investigations will focus on resolving lncRNA-binding motifs, which could yield new RNA-based targets for the prevention and treatment of this disease.

The IncRNA-based therapeutic strategies currently remain limited in vivo application, due to the relatively poor stability and intracellular uptake of drugs. Exosome delivery systems can greatly increase their bioavailability by preserving integrity, and the engineering of liganddependent exosome membranes that target specific brain tissues is also drawing interest, making therapy more efficient and target-specific.

\footnotetext{
Abbreviations

Akt: Protein kinase B; ALKBH5: A-ketoglutarate-dependent dioxygenase alkB homolog 5; ASO: Antisense oligonucleotide; BCl-x: B-cell lymphoma x; BET: Bromodomain and extraterminal; BRK: Breast tumor kinase; BTB: Bloodtumor barrier; CASC2: Cancer susceptibility candidate 2; circRNA: Circular RNA; ciRNA: Circular intronic RNA; CRNDE: Colorectal neoplasia differentially expressed; CSC: Cancer stem-cell-like; CXCR7: Chemokine receptor 7b;

EMT: Epithelial-to-mesenchymal transition; EOC: Epithelial ovarian cancer cell; eRNA: Enhancer-associated RNA; ERV: Endogenous retrovirus; ESM-

1: Endothelial cell-specific molecule 1; EZH2: Enhancer of zeste homolog 2; FLC: FLOWERING LOCUS C; FOXM1-AS: Forkhead box protein M1 antisense transcript; GBM: Glioblastoma multiform; GECs: Glioma-associated endothelial
} 
cells; GSCs: GBM stem-like cells; H3K27me3: Histone 3 lysine 27 trimethylation; H3K56ac: Histone 3 lysine 56 acetylation; HIF1a: Hypoxia-inducible factora; hnRNP: Heterogeneous nuclear ribonucleoprotein; HOTAIR: HOX transcript antisense RNA; HOXA11-AS: Homeobox protein Hox-A11 antisense RNA 1; HULC: Human universal load carrier; lincRNAs: Intergenic IncRNAs; LINK-A: Long intergenic noncoding RNA for kinase activation; LncRNAs: Long non-coding RNAs; MALAT1: Metastasisassociated lung adenocarcinoma transcript 1; MEG3: Maternally expressed gene 3; MMP 3: Matrix metalloproteinase 3; MTA2: Metastasis-associated protein 2; mTOR: Mechanistic target of rapamycin; NEAT1_2: Nuclear enriched abundant transcript 1 the long isoform; ORF: Open reading frame; PI3K: Phosphatidylinositol-4,5-bisphosphate 3-kinase; PRC2: Polycomb repressive complex 2; PROMPT: Promoter upstream transcript PTBP1: Polypyrimidine tract-binding protein 1; RISC: RNA-induced silencing complex; RNase P: Ribonuclease P; SERCA: Sarcoplasmic reticulum $\mathrm{Ca}^{2+}$-ATPase; SHP: Small heterodimer partnerm6AN6-Methyladenosine; siRNA: Small interfering RNA; SIRT6: Sirtuin-6; Snail: Snail1; SNHG5: Small nucleolar RNA hos gene 5; sno-IncRNA: SnoRNA-ended IncRNA; snoRNA: Small nucleolar RNA; SPA: 5' SnoRNA-ended and 3'-polyadenylated IncRNA; SPAR: Small regulatory polypeptide of amino acid response; TAM: Tumor associated macrophage; TERRA: Telomeric repeat-containing RNA; TMZ: Temozolomide; TrxG: Trithorax Group proteins; TUG1: Taurine upregulated gene 1; TUSC7: Tumor suppressor candidate 7; USF: Stimulating factor; XIST: X-inactive specific transcript

\section{Funding}

This work was supported by National Key Technology Research and Development program of the Ministry of Science and Technology of China (2014BAI04B02) and Graduate Research and Innovation Projects of Central South University (Grant 2017zzts012).

\section{Authors' contributions}

ZP wrote the manuscript and drew the figures. $\mathrm{CL}$ and MW made corrections for the manuscript. MW gave the idea of the review and made the final corrections for the manuscript. All authors read and approved the final manuscript under the supervision of MW before the submission.

\section{Competing interests}

The authors declare that they have no competing interests.

\section{Publisher's Note}

Springer Nature remains neutral with regard to jurisdictional claims in published maps and institutional affiliations.

Received: 15 September 2017 Accepted: 8 February 2018 Published online: 19 February 2018

\section{Reference}

1. Ulitsky I, Bartel DP. lincRNAs: genomics, evolution, and mechanisms. Cell. 2013;154(1):26-46.

2. Lagarde J, et al. Extension of human IncRNA transcripts by RACE coupled with long-read high-throughput sequencing (RACE-Seq). Nat Commun. 2016;7:12339.

3. Deveson IW, et al. The dimensions, dynamics, and relevance of the mammalian noncoding transcriptome. Trends Gen Tig. 2017;33(7):464-78.

4. Almeida M, et al. PCGF3/5-PRC1 initiates Polycomb recruitment in X chromosome inactivation. Science. 2017;356(6342):1081-84.

5. Chen LL. Linking long noncoding RNA localization and function. Trends Biochem Sci. 2016:41(9):761-72.

6. Hu X, et al. The role of long noncoding RNAs in cancer: the dark matter matters. Curr Opin Genet Dev. 2017:48:8-15.

7. Shi J, et al. Long non-coding RNA in glioma: signaling pathways. Oncotarget. 2017:8(16):27582-92.

8. Yan $Y$, et al. An insight into the increasing role of LncRNAs in the pathogenesis of gliomas. Front Mol Neurosci. 2017;10(24516):53.

9. Wang $Q$, et al. A novel cell cycle-associated IncRNA, HOXA11-AS, is transcribed from the 5-prime end of the HOXA transcript and is a biomarker of progression in glioma. Cancer Lett. 2016;373(2):251-9.

10. Jing SY, et al. Expression of long non-coding RNA CRNDE in glioma and its correlation with tumor progression and patient survival. Eur Rev Med Pharmacol Sci. 2016;20(19):3992-6.
11. Wu F, et al. Upregulation of long noncoding RNA HOXA-AS3 promotes tumor progression and predicts poor prognosis in glioma. Oncotarget. 2017:8(32):53110-23

12. St Laurent G, Wahlestedt C, Kapranov P. The landscape of long noncoding RNA classification. Trends Genet. 2015;31(5):239-51.

13. Rinn JL, Chang HY. Genome regulation by long noncoding RNAs. Annu Rev Biochem. 2012;81(1):145-66.

14. Ma L, Bajic VB, Zhang Z. On the classification of long non-coding RNAs. RNA Biol. 2013;10(6):925-33.

15. Li W, et al. Functional roles of enhancer RNAs for oestrogen-dependent transcriptional activation. Nature. 2013;498(7455):516-20

16. Quinn JJ, Chang HY. Unique features of long non-coding RNA biogenesis and function. Nat Rev Genet. 2016:17(1):47-62.

17. Jain AK, et al. LncPRESS1 is a p53-regulated LnCRNA that safeguards pluripotency by disrupting SIRT6-mediated de-acetylation of histone H3K56. Mol Cell. 2016;64(5):967-81.

18. Lin A, et al. TheLINK-AlncRNA activates normoxic HIF1a signaling in triplenegative breast cancer. Nat Cell Biol. 2016;18(2):213-24.

19. Somarowthu $\mathrm{S}$, et al. HOTAIR forms an intricate and modular secondary structure. Mol Cell. 2015;58(2):353-61.

20. Wu H, Yang L, Chen LL. The diversity of long noncoding RNAs and their generation. Trends Genet. 2017;33(8):540-52.

21. $\mathrm{Wu} \mathrm{H}$, et al. Unusual processing generates SPA LncRNAs that sequester multiple RNA binding proteins. Mol Cell. 2016;64(3):534-48.

22. Zhang $Y$, Yang L, Chen LL. Life without a tail: new formats of long noncoding RNAs. Int J Biochem Cell Biol. 2014;54(1):338-49.

23. Meng $S$, et al. CircRNA: functions and properties of a novel potential biomarker for cancer. Mol Cancer. 2017;16(1):94.

24. Zhang Y, et al. Circular intronic long noncoding RNAs. Mol Cell. 2013;51(6): 792-806.

25. Chen $\mathrm{Q}$, et al. Long non-coding RNA NEAT1, regulated by the EGFR pathway, contributes to glioblastoma progression through the WNT/betacatenin pathway by scaffolding EZH2. Clin Cancer Res. 2017;24(3):684-95.

26. Quagliata $L$, et al. Long noncoding RNA HOTTIP/HOXA13 expression is associated with disease progression and predicts outcome in hepatocellular carcinoma patients. Hepatology. 2014:59(3):911-23.

27. Huang $B$, et al. Long non-coding antisense RNA KRT7-AS is activated in gastric cancers and supports cancer cell progression by increasing KRT7 expression. Oncogene. 2016;35(37):4927-36.

28. Singh $\mathrm{R}$, et al. Regulation of alternative splicing of $\mathrm{BCl}-\mathrm{x}$ by $\mathrm{BC} 200$ contributes to breast cancer pathogenesis. Cell Death Dis. 2016;7(6):e2262.

29. Zhang $L$, et al. Long noncoding RNA MEG3 induces cholestatic liver injury by interaction with PTBP1 to facilitate shp mRNA decay. Hepatology. 2017; 65(2):604-15.

30. Zheng J, et al. CRNDE promotes malignant progression of glioma by attenuating miR-384/PIWIL4/STAT3 axis. Mol Ther J Am Soc Gene Ther. 2016:24(7):1199-215

31. Li D, et al. Long noncoding RNA HULC modulates the phosphorylation of YB-1 through serving as a scaffold of extracellular signal-regulated kinase and YB-1 to enhance hepatocarcinogenesis. Hepatology. 2017;65(5):1612-27.

32. Zhao $L$, et al. Long non-coding RNA SNHG5 suppresses gastric cancer progression by trapping MTA2 in the cytosol. Oncogene. 2016;35(44):5770-80.

33. Andrews SJ, Rothnagel JA. Emerging evidence for functional peptides encoded by short open reading frames. Nat Rev Genet. 2014;15(3):193-204.

34. Anderson DM, et al. A micropeptide encoded by a putative long noncoding RNA regulates muscle performance. Cell. 2015;160(4):595-606.

35. Matsumoto A, et al. mTORC1 and muscle regeneration are regulated by the LINC00961-encoded SPAR polypeptide. Nature. 2017;541(7636):228-32.

36. Nelson BR, et al. A peptide encoded by a transcript annotated as long noncoding RNA enhances SERCA activity in muscle. Science. 2016;351(6270): $271-5$.

37. Huang JZ, et al. A peptide encoded by a putative InCRNA HOXB-AS3 suppresses colon cancer growth. Mol Cell. 2017;68(1):171-84.

38. Barile L, Vassalli G. Exosomes: therapy delivery tools and biomarkers of diseases. Pharmacol Ther. 2017;174:63-78.

39. $\mathrm{Qu} \mathrm{L}$, et al. Exosome-transmitted IncARSR promotes Sunitinib resistance in renal cancer by acting as a competing endogenous RNA. Cancer Cell. 2016; 29(5):653-68.

40. Conigliaro A, et al. CD90+ liver cancer cells modulate endothelial cell phenotype through the release of exosomes containing H19 IncRNA. Mol Cancer. 2015;14(1):155. 
41. Wu Q, et al. Suppression of endothelial cell migration by tumor associated macrophage-derived exosomes is reversed by epithelial ovarian cancer exosomal IncRNA. Cancer Cell Int. 2017;17(1):62.

42. Wang $Y$, et al. CRNDE, a long-noncoding RNA, promotes glioma cell growth and invasion through mTOR signaling. Cancer Lett. 2015;367(2):122-8.

43. Ke J, et al. Knockdown of long non-coding RNA HOTAIR inhibits malignant biological behaviors of human glioma cells via modulation of miR-326. Oncotarget. 2015;6(26):21934-49.

44. Zhao X, et al. GAS5 suppresses malignancy of human glioma stem cells via a miR-196a-5p/FOXO1 feedback loop is. Biochim Biophys Acta. 2017; 1864(10):1605-17.

45. Liao $Y$, et al. LncRNA CASC2 interacts with miR-181a to modulate glioma growth and resistance to TMZ through PTEN pathway.J Cell Biochem. 2017; 118(7):1889-99.

46. Deguchi S, et al. Oncogenic effects of evolutionarily conserved noncoding RNA ECONEXIN on gliomagenesis. Oncogene. 2017;36(32):4629-40.

47. Katsushima $\mathrm{K}$, et al. Targeting the notch-regulated non-coding RNA TUG1 for glioma treatment. Nat Commun. 2016;7:13616.

48. Yao Y, et al. Knockdown of long non-coding RNA XIST exerts tumorsuppressive functions in human glioblastoma stem cells by up-regulating miR-152. Cancer Lett. 2015:359(1):75-86.

49. Dixit $D$, et al. Messenger RNA methylation regulates glioblastoma tumorigenesis. Cancer Cell. 2017;31(4):474-5.

50. Zhang S, et al. m6A demethylase ALKBH5 maintains Tumorigenicity of glioblastoma stem-like cells by sustaining FOXM1 expression and cell proliferation program. Cancer Cell. 2017;31(4):591-606. e6

51. Pandey GK, et al. The risk-associated long noncoding RNA NBAT-1 controls neuroblastoma progression by regulating cell proliferation and neuronal differentiation. Cancer Cell. 2014;26(5):722-37.

52. Zhang $\mathrm{K}$, et al. Long non-coding RNA HOTAIR promotes glioblastoma cell cycle progression in an EZH2 dependent manner. Oncotarget. 2015;6(1): 537-46.

53. Teng $H$, et al. Role of HCP5-miR-139-RUNX1 feedback loop in regulating malignant behavior of glioma cells. Mol Ther. 2016;24(10):1806-22.

54. Cao $\mathrm{S}$, et al. Tumor-suppressive function of long noncoding RNA MALAT1 in glioma cells by suppressing miR-155 expression and activating FBXW7 function. Am J Cancer Res. 2016;6(11):2561-74.

55. Shang C, et al. Long non-coding RNA TUSC7, a target of miR-23b, plays tumor-suppressing roles in human gliomas. Front Cell Neurosci. 2016;10(6): 235.

56. Han Y, et al. Tumor-suppressive function of long noncoding RNA MALAT1 in glioma cells by downregulation of MMP2 and inactivation of ERK/MAPK signaling. Cell Death Dis. 2016;7(3):e2123.

57. Jia $\mathrm{P}$, et al. Long non-coding RNA H19 regulates glioma angiogenesis and the biological behavior of glioma-associated endothelial cells by inhibiting microRNA-29a. Cancer Lett. 2016;381(2):359-69.

58. Yu H, et al. Knockdown of long non-coding RNA XIST increases bloodtumor barrier permeability and inhibits glioma angiogenesis by targeting miR-137. Oncogene. 2017;6(3):e303.

59. Cheng $Z$, et al. Long non-coding RNA XIST promotes glioma Tumorigenicity and angiogenesis by acting as a molecular sponge of miR-429. J Cancer. 2017;8(19):4106-16.

60. Zhu Y, et al. HULC long noncoding RNA silencing suppresses angiogenesis by regulating ESM-1 via the PI3K/Akt/mTOR signaling pathway in human gliomas. Oncotarget. 2016;7(12):14429-40.

61. Ma J, et al. Knockdown of long non-coding RNA MALAT1 increases the blood-tumor barrier permeability by up-regulating miR-140. Biochim Biophys Acta. 2016;1859(2):324-38.

62. Sa $L$, et al. The role of HOTAIR/miR-148b-3p/USF1 on regulating the permeability of BTB. Front Mol Neurosci. 2017;10:194.

63. Cai $\mathrm{H}$, et al. The long noncoding RNA TUG1 regulates blood-tumor barrier permeability by targeting miR-144. Oncotarget. 2015;6(23):19759-79.

64. Messaoudi K, Clavreul A, Lagarce F. Toward an effective strategy in glioblastoma treatment. Part I: resistance mechanisms and strategies to overcome resistance of glioblastoma to temozolomide. Drug Discov Today. 2015:20(7):899-905.

65. Li $\mathrm{H}$, et al. Long non-coding RNA MALAT1 decreases the sensitivity of resistant glioblastoma cell lines to Temozolomide. Cell Physiol Biochem. 2017;42(3):1192-1201.

66. Huarte M. The emerging role of IncRNAs in cancer. Nat Med. 2015;21(11): $1253-61$.
67. Di Meo A, et al. Liquid biopsy: a step forward towards precision medicine in urologic malignancies. Mol Cancer. 2017;16(1):80.

68. Yuan W, et al. Circulating LncRNAs serve as diagnostic markers for hepatocellular carcinoma. Cell Physiol Biochem. 2017:44(1):125-32.

69. Gourlay J, et al. The emergent role of exosomes in glioma. J Clin Neurosci. 2017;35:13-23

70. Matsui M, Corey DR. Non-coding RNAs as drug targets. Nat Rev Drug Discov. 2017;16(3):167-79.

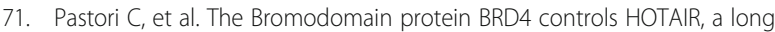
noncoding RNA essential for glioblastoma proliferation. Proc Natl Acad Sci U S A. 2015:112(27):8326-31.

72. Arun $\mathrm{G}$, et al. Differentiation of mammary tumors and reduction in metastasis upon Malat1 IncRNA loss. Genes Dev. 2016:30(1):34-51.

73. Cheng $\mathrm{CJ}$, et al. MicroRNA silencing for cancer therapy targeted to the tumour microenvironment. Nature. 2015:518(7537):107-10.

74. Özeş AR, et al. Therapeutic targeting using tumor specific peptides inhibits long non-coding RNA HOTAIR activity in ovarian and breast cancer. Sci Rep. 2017;7(1):894.

75. Monroig Pdel C, et al. Small molecule compounds targeting miRNAs for cancer therapy. Adv Drug Deliv Rev. 2015;81:104-16.

76. Zhang $\mathrm{R}$, Jin H, Lou F. The long non-coding RNA TP73-AS1 interacted with miR-142 to modulate brain glioma growth through HMGB1/RAGE pathway. J Cell Biochem. 2017. [Epub ahead of print].

77. Li DX, et al. The long non-coding RNA CRNDE acts as a ceRNA and promotes glioma malignancy by preventing miR-136-5p-mediated downregulation of Bcl-2 and Wnt2. Oncotarget. 2017;8(50):88163-78.

78. Li C, et al. H19 derived microRNA-675 regulates cell proliferation and migration through CDK6 in glioma. Am J Transl Res. 2015;7(10):1747-64.

79. Su R, et al. Knockdown of SOX2OT inhibits the malignant biological behaviors of glioblastoma stem cells via up-regulating the expression of miR-194-5p and miR-122. Mol Cancer. 2017;16(1):171.

80. Liu C, et al. CASC2C as an unfavorable prognosis factor interacts with miR101 to mediate astrocytoma tumorigenesis. Cell Death Dis. 2017:8(3):e2639.

81. Li J, et al. LncRNA TUG1 acts as a tumor suppressor in human glioma by promoting cell apoptosis. Exp Biol Med (Maywood). 2016:241(6):644-9.

82. Zhao X, et al. Gas5 exerts tumor-suppressive functions in human glioma cells by targeting miR-222. Mol Ther. 2015:23(12):1899-911.

\section{Submit your next manuscript to BioMed Central and we will help you at every step:}

- We accept pre-submission inquiries

- Our selector tool helps you to find the most relevant journal

- We provide round the clock customer support

- Convenient online submission

- Thorough peer review

- Inclusion in PubMed and all major indexing services

- Maximum visibility for your research

Submit your manuscript at www.biomedcentral.com/submit
) Biomed Central 